\title{
Uranyl lon Coordination by Benzene-1,2,3-tricarboxylate: Building Chains and Networks from Binuclear Bricks
}

\author{
Dr. Pierre Thuéry*[a] and Dr. Jack Harrowfield ${ }^{*[b]}$ \\ [a] Université Paris-Saclay, CEA, CNRS, NIMBE, 91191 Gif-sur-Yvette, France \\ E-mail: pierre.thuery@cea.fr \\ http://iramis.cea.fr/nimbe/ \\ ${ }^{[b]}$ ISIS, Université de Strasbourg, 8 allée Gaspard Monge, 67083 Strasbourg, France \\ E-mail: harrowfield@unistra.fr \\ https://isis.unistra.fr/fr/
}

\begin{abstract}
Benzene-1,2,3-tricarboxylic acid $\left(123 \mathrm{btcH}_{3}\right)$ was used to synthesize 7 uranyl ion complexes under hydrosolvothermal conditions, in the presence of different structure-directing agents. $\left.[\mathrm{Zn} \text { (phen) })_{3}\right]\left[\mathrm{Zn}_{2}(123 \mathrm{btc})(\text { phen })_{4}\right]\left[\left(\mathrm{UO}_{2}\right)_{2}(123 \mathrm{btc})_{2}(\mathrm{OH})\left(\mathrm{CH}_{3} \mathrm{CN}\right)\right] \cdot 3 \mathrm{H}_{2} \mathrm{O}(\mathbf{1}$, phen = 1,10-phenanthroline), the only discrete species in the series, crystallizes as a binuclear, cup-shaped dimer. Both $\left[\mathrm{PPh}_{3} \mathrm{Me}\right]\left[\mathrm{UO}_{2}(123 \mathrm{btc})\right](2)$ and $\left[\mathrm{C}\left(\mathrm{NH}_{2}\right)_{3}\right]\left[\mathrm{UO}_{2}(123 \mathrm{btc})\right] \cdot 0.5 \mathrm{H}_{2} \mathrm{O}(3)$ contain anionic, monoperiodic coordination polymers based on quasi-planar, binuclear $\left(\mathrm{UO}_{2}\right)_{2}(123 \mathrm{btc})_{2}{ }^{2-}$ subunits in which two oxygen atoms of each ligand are uncoordinated. Similar chains are found in $\left[\mathrm{UO}_{2}(123 \mathrm{btc}) \mathrm{K}(18 \mathrm{C} 6)\right] \cdot \mathrm{H}_{2} \mathrm{O}(4,18 \mathrm{C} 6=18$-crown-6), the potassium cations being decorating groups bound to carboxylato and uranyl oxo donors. An analogous decorating role to monoperiodic polymers is played by $\mathrm{UO}_{2}(\mathrm{DMF})_{2}\left(\mathrm{H}_{2} \mathrm{O}\right)_{2}{ }^{2+}$ cations in $\left[\left(\mathrm{UO}_{2}\right)_{3}(123 \mathrm{btc})_{2}(\mathrm{DMF})_{2}\left(\mathrm{H}_{2} \mathrm{O}\right)_{2}\right](5)$, while bridging of chains by $\mathrm{UO}_{2}(\mathrm{NMP})_{3}{ }^{2+}$ cations in $\left[\left(\mathrm{UO}_{2}\right)_{3}(123 \mathrm{btc})_{2}(\mathrm{NMP})_{3}\right]$ (6) yields a diperiodic network with $\mathrm{V}_{2} \mathrm{O}_{5}$ topology. $\left[\mathrm{NH}_{4}\right]\left[\mathrm{UO}_{2}(123 \mathrm{btc})\right](7)$, which does not contain the dimeric subunit found in the other cases, crystallizes as a diperiodic network with sql topology, the layers being associated through hydrogen bonding interactions with the ammonium counterions.
\end{abstract}




\section{Introduction}

While the coordination and structural chemistry of uranyl ion polycarboxylate complexes generally has been very extensively investigated, ${ }^{[1-6]}$ rather scant attention has been given to the tricarboxylate species benzene-1,2,3-tricarboxylate $\left(123 \mathrm{btc}^{3-}\right.$, "hemimellitate") ${ }^{[7,8]}$ (two complexes with $\mathrm{U}^{\mathrm{IV}}$ having however also been reported, ${ }^{\left[{ }^{[9]}\right.}$ as well as two uranyl ion complexes with the derivative 5-nitro-benzene-1,2,3-tricarboxylate $\left.{ }^{[10]}\right)$. This is despite the fact that the one $k$ nown ${ }^{[7,8]}$ structure of a uranyl ion complex, of composition $\left[\left(\mathrm{UO}_{2}\right)_{3}(123 \mathrm{btc})_{2}\left(\mathrm{H}_{2} \mathrm{O}\right)_{4}\right]$, has shown a triperiodic coordination polymer to be present, raising the obvious prospect, amongst others, ${ }^{[7]}$ of obtaining porous solids with potential application as heterogeneous photo-oxidation catalysts, a prospect which has been realized in some related systems, e.g. ${ }^{[11]}$. As for simpler ligands, such as phthalate, ${ }^{[12]}$ involving adjacent carboxylate groups on an aromatic platform, chelation of uranyl ion is not compatible with coplanarity of the carboxylate groups involved and this influence in $123 \mathrm{btc}^{3-}$, probably amplified by repulsive interactions involving the third carboxylate, results in the 2-carboxylato group of $\left[\left(\mathrm{UO}_{2}\right)_{3}(123 \mathrm{btc})_{2}\left(\mathrm{H}_{2} \mathrm{O}\right)_{4}\right]$ lying almost perpendicular to the benzene ring, while the 1- and 3-carboxylato groups are both almost coplanar with it. This has been considered ${ }^{[7]}$ a factor giving rise to the triperiodic nature of the coordination polymer present. Following our previous work on uranyl complexes with benzene-1,2,4tricarboxylate, ${ }^{[13]}$ and so as to further investigate the behaviour of $123 \mathrm{btc}^{3-}$ as a ligand on uranyl ion, we have prepared and structurally characterized seven complexes in which the metal:ligand ratio is either $1.5: 1$, as in the earlier work, or 1:1, a stoichiometry resulting in anionic complexes subject to the influence of various additional cations used as structuredirecting agents. 


\section{Results and Discussion}

The compound $\left[\mathrm{Zn}(\text { phen })_{3}\right]\left[\mathrm{Zn}_{2}(123 \mathrm{btc})(\text { phen })_{4}\right]\left[\left(\mathrm{UO}_{2}\right)_{2}(123 \mathrm{btc})_{2}(\mathrm{OH})\left(\mathrm{CH}_{3} \mathrm{CN}\right)\right] \cdot 3 \mathrm{H}_{2} \mathrm{O}$

where phen is 1,10-phenanthroline, is the only case in the present series of a zero-periodic, discrete complex (Figure 1). The unexpected composition involving two different zinccontaining counterions seemingly results from the lack of sufficient phen in the reaction



Figure 1. (a) View of complex 1. Displacement ellipsoids are drawn at the $30 \%$ probability level. The $\left[\mathrm{Zn}(\text { phen })_{3}\right]^{2+}$ counterion, solvent molecules and hydrogen atoms are omitted, and only one position of the disordered parts is shown. Symmetry codes: $\mathrm{i}=1-x, y, 1 / 2-z ; \mathrm{j}=1-x, y, 3 / 2-z$. (b) View of the packing with uranium coordination polyhedra yellow and those of zinc blue. 
mixture to block all coordination sites on the $\mathrm{Zn}^{\prime \prime}$ present. The unique uranium atom is in a pentagonal-bipyramidal environment, being chelated by two carboxylate groups from two $123 \mathrm{btc}^{3-}$ ligands, with formation of two 7-membered chelate rings, and either an hydroxide anion or an acetonitrile molecule, these species being disordered on the same coordination site with a 1:1 ratio ensuring charge balance (see Experimental Section) [U-O(oxo), 1.773(4)

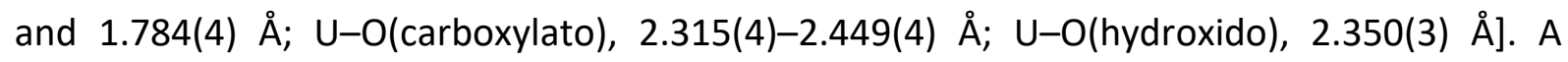
binuclear uranyl complex with twofold rotation symmetry is thus formed, in which the benzene rings project from the same side of the $\mathrm{U}_{2} \mathrm{O}_{6}$ mean plane, making the whole unit cup-shaped. The two counterions $\left[\mathrm{Zn}(\text { phen })_{3}\right]^{2+}$ and $\left[\mathrm{Zn}_{2}(123 \mathrm{btc})(\text { phen })_{4}\right]^{+}$have also twofold rotation symmetry. The $123 \mathrm{btc}^{3-}$ ligand in the latter, binuclear cation forms 7 -membered chelate rings on both $\mathrm{Zn}$ " centres to form a chiral species, perhaps as a result of repulsions due to the bulk of the additional two phen ligands on each metal centre. In the binuclear uranyl anion, one oxygen donor of each carboxylate is uncoordinated but all are involved in other weak interactions. Thus, those on the 1- and 3-carboxylates are close to oxygen atoms assigned to water molecules, with $0 \cdots 0$ distances of $2.744(11)$ and $2.907(17) \AA$, and they appear to be involved in a chain of hydrogen bonded water molecules eventually connected to the uncoordinated carboxylate oxygen atoms of the $\mathrm{Zn}$ dimer [OO.O distance, $2.780(8) \AA]$, although the inability to locate the hydrogen atoms of the water molecules renders this conclusion uncertain. The uncoordinated 2-carboxylate oxygen atom which, as seen in the other complexes described here, can interact in various ways, is involved in two $\mathrm{CH} \cdots \mathrm{O}$

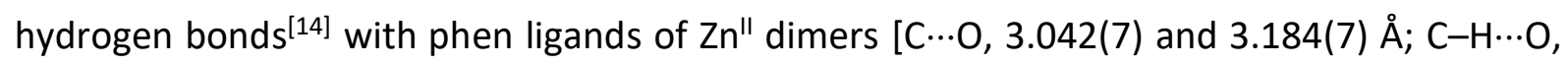
130 and $136^{\circ}$ ], which renders the associated anion chiral, as of course are both the countercations, though equal amounts of both enantiomeric forms of all three species are present in the structure, so that the crystal is not chiral. The two cationic moieties are 
possibly involved in several parallel-displaced $\pi$-stacking interactions with each other and their symmetry equivalents, as revealed from an analysis of short contacts with PLATON ${ }^{[15]}$

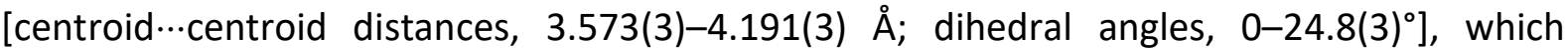
results in the formation of undulating cationic layers parallel to (010), between which the anionic complexes are located, the packing containing no free space (Kitaigorodski packing index (KPI) calculated with PLATON, 0.69 , with disorder excluded).

The discrete nature of complex 1 , exceptional in this series, is due to the presence of the terminal hydroxide and acetonitrile ligands, which are easily replaced by donors from the array of uncoordinated carboxylate oxygen atoms. This is the case in $\left[\mathrm{PPh}_{3} \mathrm{Me}\right]\left[\mathrm{UO}_{2}(123 \mathrm{btc})\right](2)$, in which the uranium atom is, as in $\mathbf{1}$, chelated by two $123 \mathrm{btc}^{3-}$ ligands and bound to one more oxygen atom from a lateral carboxylate group of another ligand, the environment being here also pentagonal-bipyramidal [U-O(oxo), 1.776(4) and

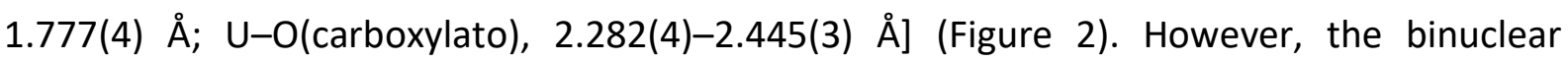
$\left[\mathrm{UO}_{2}(123 \mathrm{btc})\right]_{2}{ }^{2-}$ moiety is here centrosymmetric, and the two aromatic rings are thus on either side of the $\mathrm{U}_{2} \mathrm{O}_{6}$ mean plane. Instead of three as in $\mathbf{1}$, there are two uncoordinated oxygen atoms in each ligand, on the central and one terminal carboxylate group. The coordination polymer formed is monoperiodic and directed along [100], and adjacent chains are arranged side-by-side in sheets parallel to (001), which are separated by layers of counterions (KPI, 0.70). Examination of the Hirshfeld surface ${ }^{[16]}$ (HS) calculated with CrystalExplorer $^{[17]}$ does not reveal significant interactions beyond dispersion between anionic strands in the layers. Interactions that appear to be more important are those of the strands with the sheets of phosphonium cations. Parallel-displaced $\pi$-stacking interactions are apparent both between anionic and cationic moieties [centroid...centroid distance, 
a
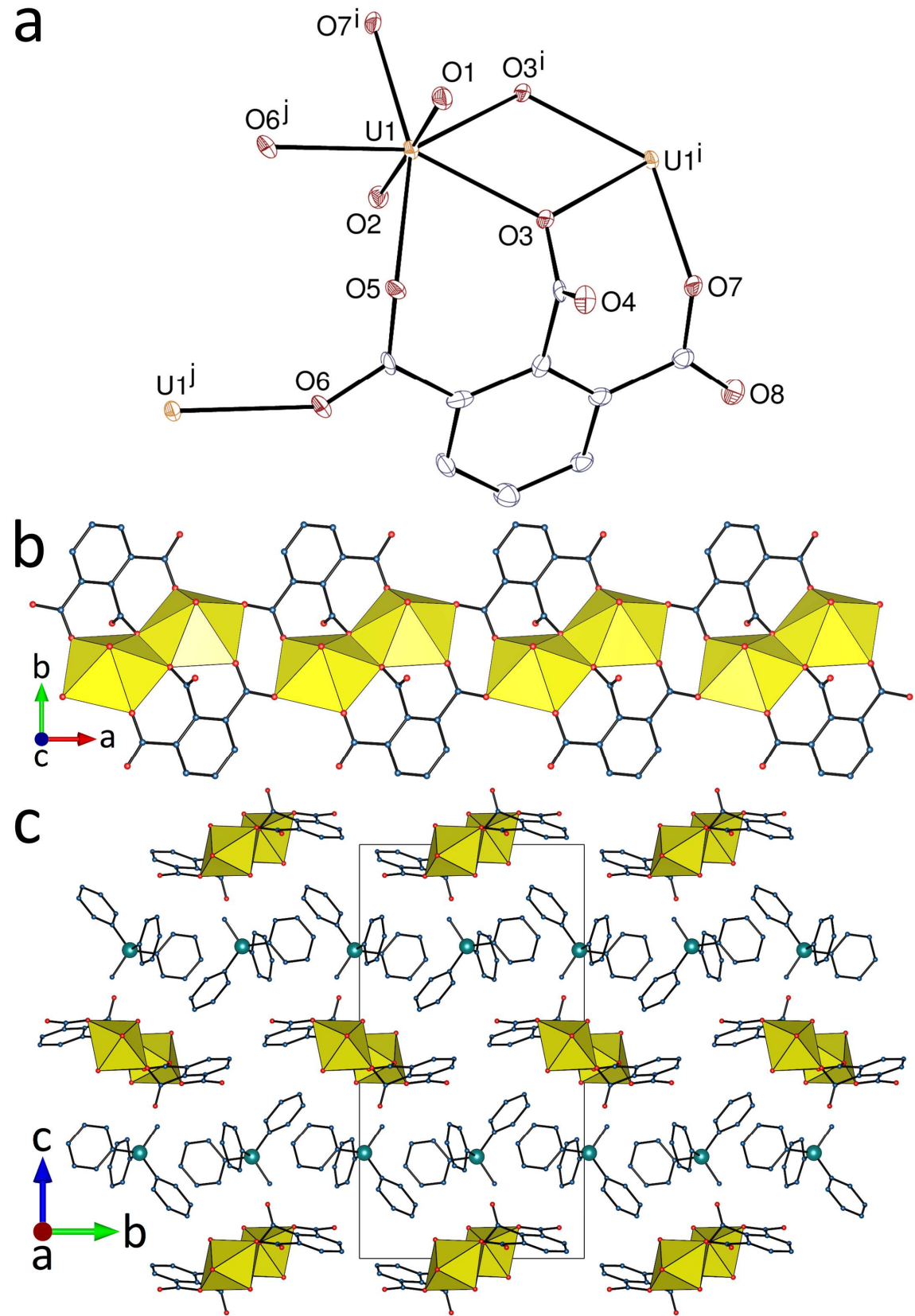

Figure 2. (a) View of complex 2. Displacement ellipsoids are drawn at the 50\% probability level. The counterion and hydrogen atoms are omitted. Symmetry codes: $\mathrm{i}=2-x,-y, 1-z ; \mathrm{j}=1-x,-y, 1-z$. (b) View of the monoperiodic coordination polymer. (c) Packing with chains viewed end-on.

4.255(3) $\AA$; dihedral angle, 29.1(3) $]$ and between $\mathrm{PPh}_{3} \mathrm{Me}^{+}$cations $\left[4.344(3) \AA\right.$ and $\left.31.7(3)^{\circ}\right]$, as well as several $\mathrm{CH} \cdots \pi$ interactions with $\mathrm{PPh}_{3} \mathrm{Me}^{+}$donors and either $123 \mathrm{btc}^{3-}$ or $\mathrm{PPh}_{3} \mathrm{Me}^{+}$

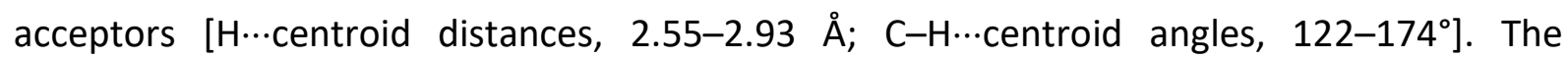
phosphonium sheets can thus be regarded as diperiodic polymers in the sense that there are 
"phenyl embrace" interactions ${ }^{[18]}$ linking cations [P...P distances, $6.4440(8)$ and 8.9543(5) Å] and their additional interactions with the uranyl polymer strands create the complete triperiodic structure of the crystal. Any given cation interacts through methyl- and phenyl$\mathrm{CH} \cdots \mathrm{O}$ contacts involving one uranyl oxygen atom in one of the adjoining layers and a phenyl- $\mathrm{CH} \cdots \mathrm{O}$ contact involving one uncoordinated carboxylate oxygen atom in the other layer [C...O distances, $3.256(7)-3.525(7) \AA ; \mathrm{C}-\mathrm{H} \cdots \mathrm{O}$ angles, $145-160^{\circ}$ ]; within a given cation sheet, the two orientations of these interactions alternate along [010].

That the monoperiodic polymer unit seen in complex $\mathbf{2}$ must have a certain stability is implied by the structure of complex $\left[\mathrm{C}\left(\mathrm{NH}_{2}\right)_{3}\right]\left[\mathrm{UO}_{2}(123 \mathrm{btc})\right] \cdot 0.5 \mathrm{H}_{2} \mathrm{O}(3)$ where the polymer is essentially identical to that in $\mathbf{2}$ despite the presence of a countercation with very different hydrogen bonding capacity to $\mathrm{PPh}_{3} \mathrm{Me}^{+}$. The asymmetric unit contains here two uranium atoms, both bound in the same manner as in 2 [U-O(oxo), 1.764(4)-1.771(4) $\AA$; UO(carboxylato), 2.308(4)-2.438(4) Å] (Figure 3). The two inequivalent 123 btc $^{3-}$ ligands, both with two uncoordinated oxygen atoms, are located here also on either side of the $\mathrm{U}_{2} \mathrm{O}_{6}$ mean plane, and the monoperiodic polymer is directed along [100]. Viewed down this direction, the array of polymer ribbons is very similar to that in complex $\mathbf{2}$ but the distribution of cations is such that the structure cannot be described as layered. Overall, the two inequivalent guanidinium cations are involved in 14 hydrogen bonds (two of them

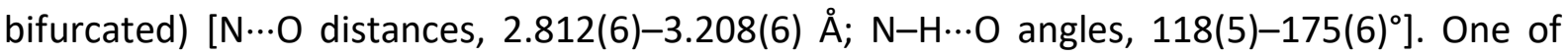
them forms a close hydrogen bonding interaction with the water molecule, through formation of a $R_{2}{ }^{1}(6)$ ring in graph set notation, ${ }^{[19]}$ and it is this aggregate which is equivalent to the phosphonium cations of complex 2 in providing multiple $\mathrm{NH}$ and $\mathrm{OH}$ donors to link two adjacent polymer ribbons. The other guanidinium cation has no associated water molecule and actually links three polymer ribbons through its $\mathrm{NH} \cdots \mathrm{O}$ interactions. The 
uncoordinated carboxylate oxygen atoms are all clearly important hydrogen bond acceptors. One parallel-displaced $\pi$-stacking interaction may exist between two $123 \mathrm{btc}^{3-}$ ligands located in different planes along the [001] direction [centroid...centroid distance, 3.785(3) $\AA$; dihedral angle, $0^{\circ}$; slippage, $\left.1.32 \AA\right]$, and the packing contains no free space (KPI, 0.71).

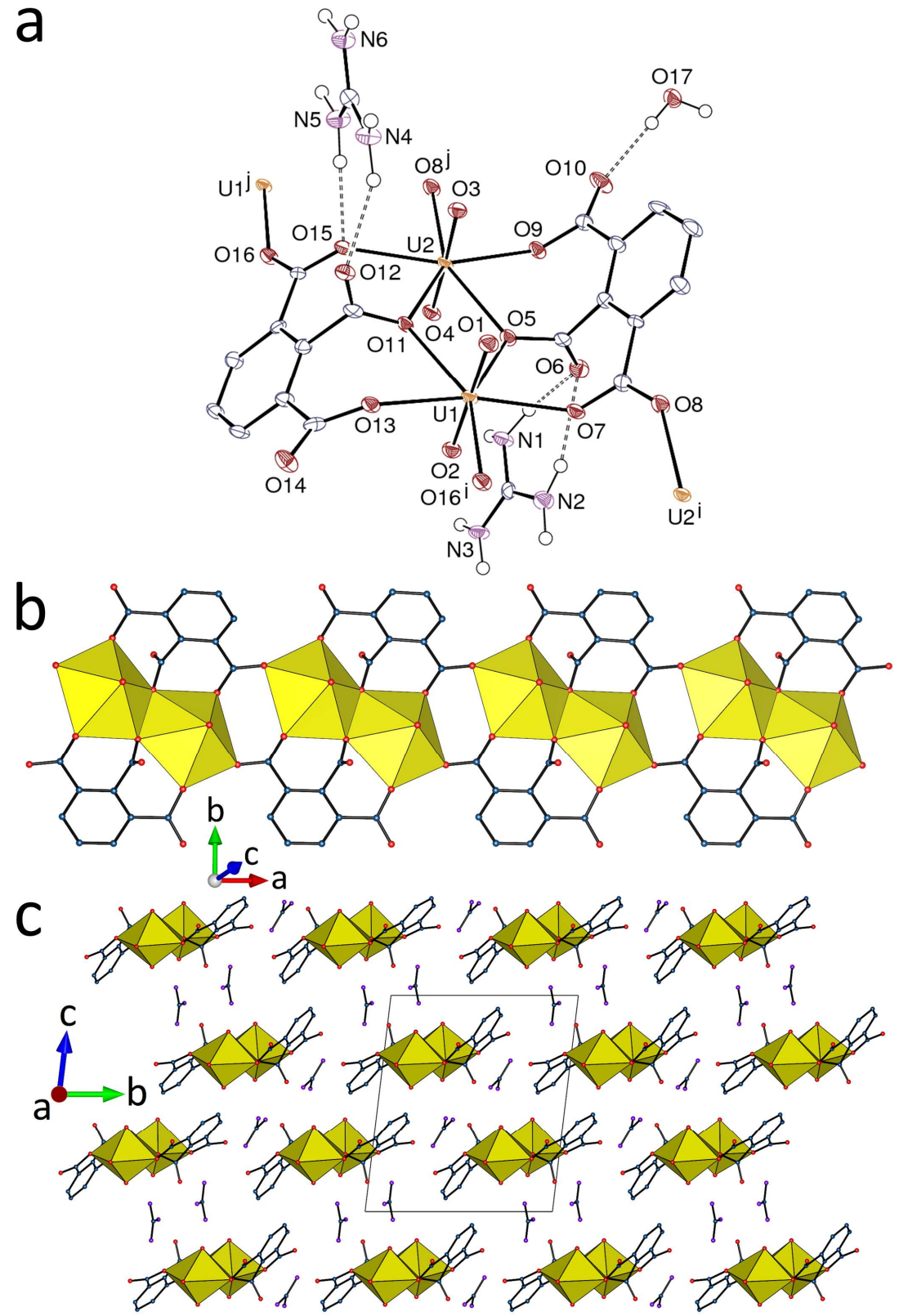

Figure 3. (a) View of complex 3 with displacement ellipsoids drawn at the $50 \%$ probability level. Carbon-bound hydrogen atoms are omitted, and hydrogen bonds are shown as dashed lines. Symmetry codes: $\mathrm{i}=x+1, y, z ; \mathrm{j}$ $=x-1, y, z$. (b) View of the monoperiodic coordination polymer. (c) Packing with chains viewed end-on. 
The presence of uncoordinated carboxylate oxygen atoms in the previous complexes allows for further bridging, either to increase the periodicity, or to add decorating groups which do not participate in polymerization. The complex $\left[\mathrm{UO}_{2}(123 \mathrm{btc}) \mathrm{K}(18 \mathrm{C} 6)\right] \cdot \mathrm{H}_{2} \mathrm{O}$ (4), where $18 \mathrm{C} 6$ is $1,4,7,10,13,16$-hexaoxacyclooctadecane or 18 -crown-6, shown in Figure 4, is a

a

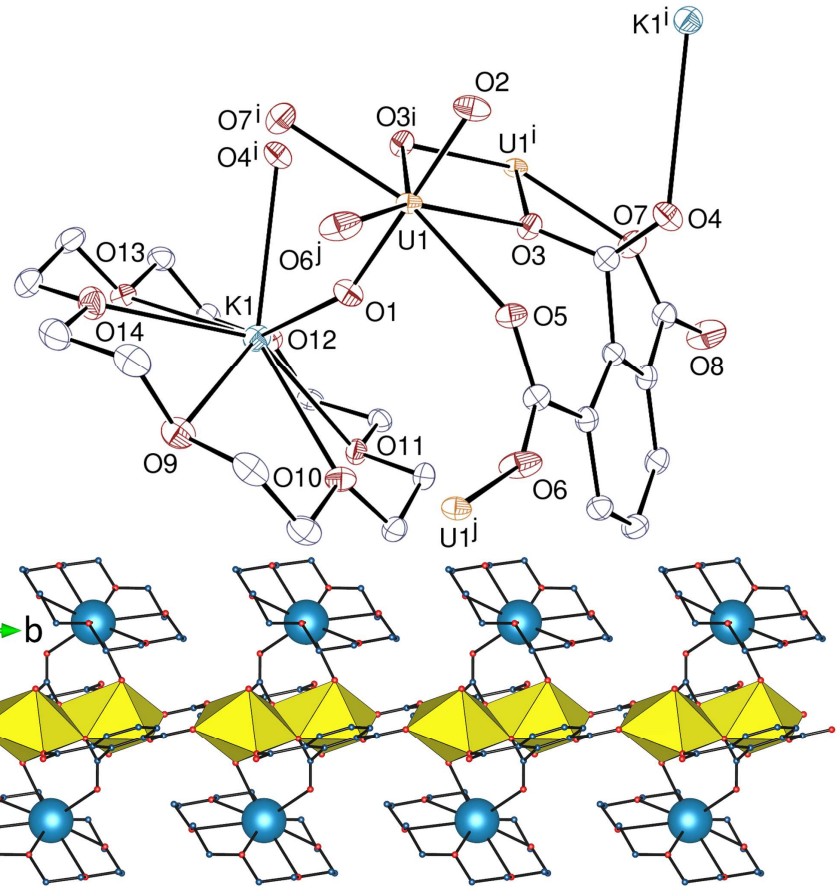

C

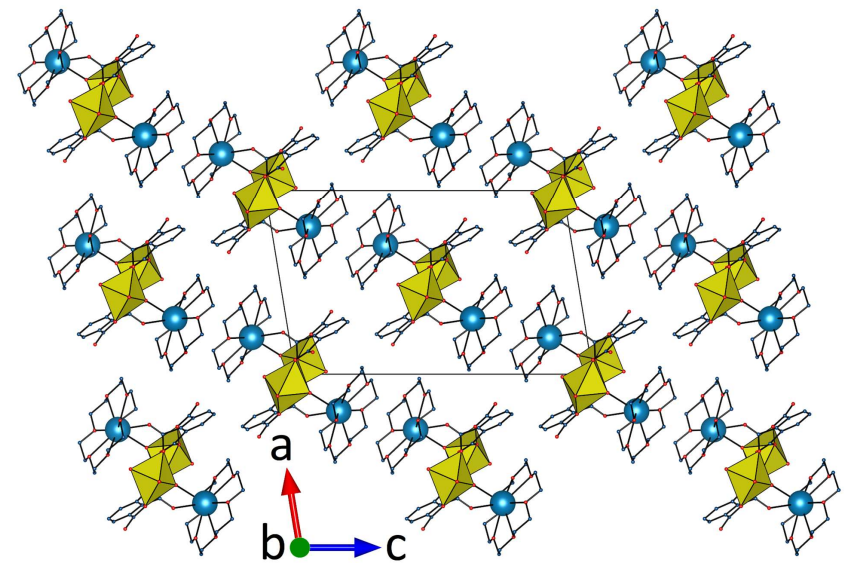

Figure 4. (a) View of complex 4 with displacement ellipsoids drawn at the $50 \%$ probability level. The solvent molecule and hydrogen atoms are omitted. Symmetry codes: $\mathrm{i}=1-x,-y, 1-z ; \mathrm{j}=1-x, 1-y, 1-z$. (b) View of the monoperiodic coordination polymer with uranium coordination polyhedra yellow and potassium ions shown as blue spheres. (c) Packing with chains viewed end-on. 
case in point. The uranium atom has the same environment as its counterparts in $\mathbf{2}$ and $\mathbf{3}$

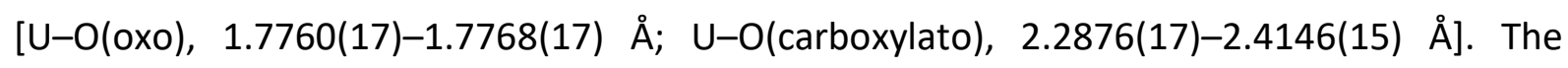
binuclear moieties formed are centrosymmetric as in $\mathbf{2}$, so that the aromatic rings are on either side of the $\mathrm{U}_{2} \mathrm{O}_{6}$ mean plane, and the monoperiodic polymer runs along [010]. One oxygen atom in a lateral carboxylate group remains uncoordinated, but the central group is now bridging the potassium and two uranium atoms in the $\mu_{3}-\kappa^{1} O: \kappa^{1} O: \kappa^{1} O^{\prime}$ mode, with a $\mathrm{K}-$ O(carboxylato) bond length of $2.9862(18) \AA$ comparable to the $\mathrm{K}-\mathrm{O}$ (ether) bond lengths [2.8273(19)-3.1063(19) Å]. The potassium cation is also bound to the uranyl oxo group 01, located on the same side of the $18 \mathrm{C} 6$ molecule as the carboxylate donor, with a $\mathrm{K}-\mathrm{O}$ bond length of $2.7739(18) \AA$ smaller than the other ones and in good agreement with the mean value of $2.77(11) \AA$ for the comparable $\mathrm{U}=\mathrm{O}-\mathrm{K}$ motifs found in the Cambridge Structural Database (CSD, Version 5.42; 32 hits, some of them involving $U^{V}$ instead of $\left.U^{V 1}\right) .{ }^{[20]}$ No significant lengthening of the $\mathrm{U}=\mathrm{O}$ bond is observed, and the $\mathrm{U}-\mathrm{O}-\mathrm{K}$ angle of $144.37(9)^{\circ}$ matches the mean value of $144(23)^{\circ}$ from the CSD. The decorating $\mathrm{K}(18 \mathrm{C} 6)$ groups protrude on either side of the flat polymeric ribbons, and they form double layers separating the uranium-containing layers parallel to $(10 \overline{1})$ in the packing (KPI, 0.75). There is here no significant weak interaction of the aromatic rings, and hydrogen bonding appears to play only a minor role in the structure, with the water molecule bonded to the uncoordinated 3carboxylate oxygen atom $\mathrm{O} 8\left[\mathrm{O} \cdots \mathrm{O}, 2.809(3) \AA \AA^{\circ} \mathrm{O}-\mathrm{H} \cdots \mathrm{O}, 173(4)^{\circ}\right]$. The HS reveals however the presence of possible, although weak, $\mathrm{CH} \cdots \mathrm{O}$ hydrogen bonding between the $18 \mathrm{C} 6$ moieties within the double layers.

Decorating groups appended to monoperiodic polymers are also present in $\left[\left(\mathrm{UO}_{2}\right)_{3}(123 \mathrm{btc})_{2}(\mathrm{DMF})_{2}\left(\mathrm{H}_{2} \mathrm{O}\right)_{2}\right](5)$, but here they are $\mathrm{UO}_{2}(\mathrm{DMF})_{2}\left(\mathrm{H}_{2} \mathrm{O}\right)_{2}{ }^{2+}$ moieties (Figure 5). The two inequivalent uranium atoms $\mathrm{U} 1$ and $\mathrm{U} 2$ are here again the core of a binuclear unit in 
a
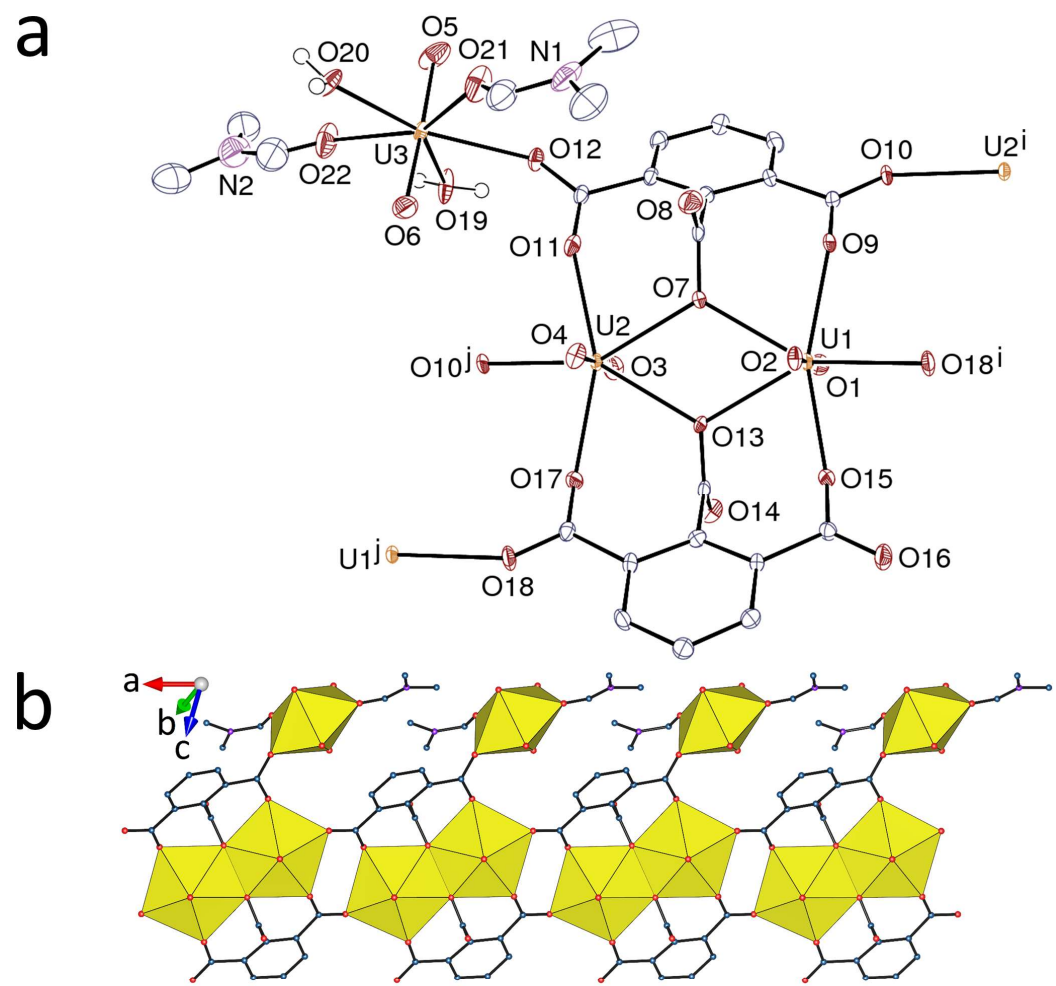

C

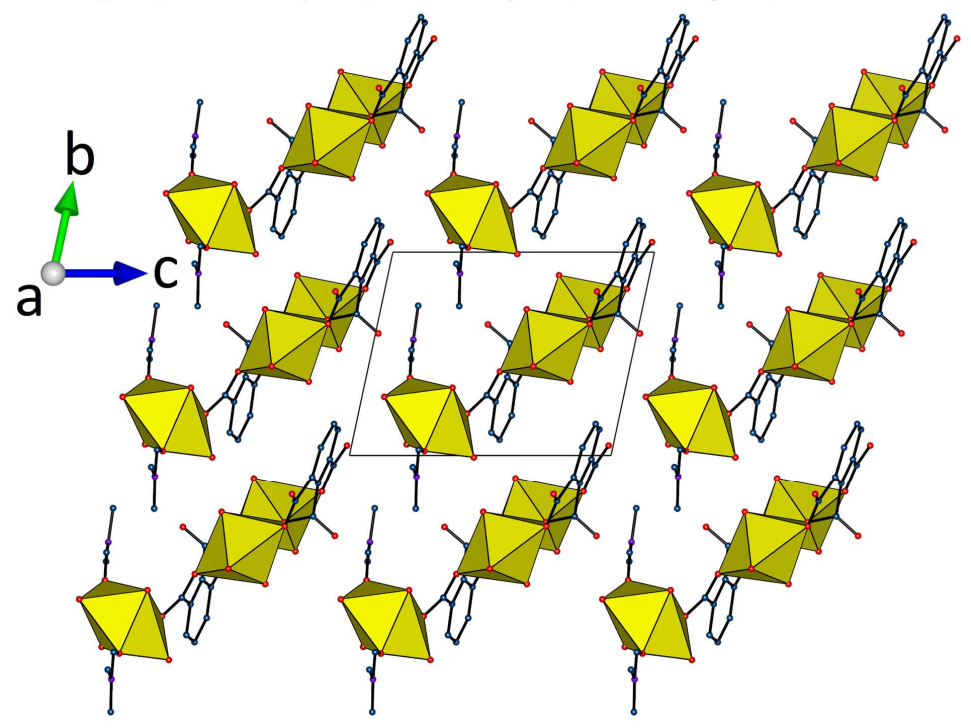

Figure 5. (a) View of complex $\mathbf{5}$ with displacement ellipsoids drawn at the 50\% probability level. Carbon-bound hydrogen atoms are omitted. Symmetry codes: $\mathrm{i}=x+1, y, z ; \mathrm{j}=x-1, y, z$. (b) View of the monoperiodic coordination polymer. (c) Packing with chains viewed end-on.

which the two aromatic rings are located on either side of the mean plane; the monoperiodic polymer based on these binuclear subunits runs along [100] and it differs 
from that in 4 by the decorating groups, containing atom U3, being bound not to the central but to one of the lateral carboxylate groups, and this along one edge of the ribbon only [U-

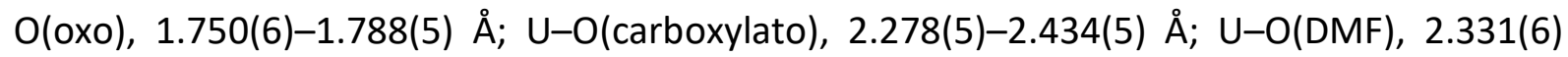
and 2.386(6) $\AA$; U-O(water), 2.394(5) and 2.481(6) $\AA$ ]. The ribbon thus extended is quasiplanar, although the decorating uranyl cation is tilted and nearly perpendicular to the mean plane. One of the ligands has one and the other two uncoordinated oxygen atoms. It is interesting to compare this structure to that of $\left[\left(\mathrm{UO}_{2}\right)_{3}(123 \mathrm{btc})_{2}\left(\mathrm{H}_{2} \mathrm{O}\right)_{4}\right]_{,}^{[7,8]}$ in which the water molecules are all coordinated, two in trans positions to one hexagonal-bipyramidal uranium centre and one on each other pentagonal-bipyramidal centre. Their hydrogen bonding interactions alone create a triperiodic array, in a manner reminiscent of that found in hydrogen bonded organic frameworks (HOFs). ${ }^{[21]}$ That this hydrogen bonding must be a factor favouring the triperiodic nature of the coordination polymer present is indicated by the consequences of formally replacing just two of the water molecules by DMF in complex 5. The ligand conformations are virtually identical in both complexes, but in $\left[\left(\mathrm{UO}_{2}\right)_{3}(123 \mathrm{btc})_{2}\left(\mathrm{H}_{2} \mathrm{O}\right)_{4}\right]$ the central carboxylate acts as a $\mu_{2}-\kappa^{1} O: \kappa^{1} O^{\prime}$ bridge between two equivalent $U^{\mathrm{VI}}$ centres, whereas in complex 5 it is bound in the $\mu_{2}-\kappa^{1} O: \kappa^{1} O$ mode. As well, in $\left[\left(\mathrm{UO}_{2}\right)_{3}(123 \mathrm{btc})_{2}\left(\mathrm{H}_{2} \mathrm{O}\right)_{4}\right]$ the ligand binds only to one metal centre through phthalate-like 7membered ring chelation, instead of two in complex $\mathbf{5}$. The polymer strands in $\mathbf{5}$ can be considered to lie in sheets parallel to $(01 \overline{1})$, the strands in any one sheet being linked together by relatively short hydrogen bonds formed by the coordinated water molecule containing $\mathrm{O} 20$ and the uncomplexed lateral carboxylate oxygen atom $\mathrm{O} 16[\mathrm{O} \cdots \mathrm{O}, 2.602(7)$ $\left.\AA ; \mathrm{O}-\mathrm{H} \cdots \mathrm{O}, 160(8)^{\circ}\right]$. Both coordinated water molecules are involved in further hydrogen bond donation, with $\mathrm{O} 20$ bound to one central uncoordinated carboxylate oxygen atom (O14) in a neighbouring sheet $\left[\mathrm{O} \cdots \mathrm{O}, 2.665(7) \AA \AA^{\circ} \mathrm{O}-\mathrm{H} \cdots \mathrm{O}, 160(8)^{\circ}\right]$, and $\mathrm{O} 19$ bound to the 
two uranyl oxo atoms $\mathrm{O} 2$ and $\mathrm{O} 4$ of a binuclear unit in the other adjoining sheet, thus making a $R_{2}{ }^{2}(8)$ ring including the two metal cations $[0 \cdots 0,2.821(7)$ and $2.881(8) \AA ̊ 0-\mathrm{O} \cdots \mathrm{O}$, $177(11)$ and $154(10)^{\circ}$ ]. This hydrogen bonding pattern leads to a triperiodic assembly of the monoperiodic strands. These additional interactions involve only one (O14) of the uncoordinated 2-carboxylate oxygen atoms, the other (O8) being involved in a $\mathrm{CH} \cdots \mathrm{O}$ interaction with a DMF methyl group $\left[\mathrm{C} \cdots \mathrm{O}, 3.169(12) \AA ̊ \mathrm{C}-\mathrm{H} \cdots \mathrm{O}, 146^{\circ}\right]$. Thus, the substitution of two water molecules with two DMF in the overall composition not only changes the relative orientation of the two water molecules on one uranium [O19-U3-O20 angle, $142.98(18)^{\circ}$ rather than $180^{\circ}$ ] but provides in DMF an hydrogen bond donor at a site considerably more remote from $U^{V I}$ than that of coordinated water, so that the complete hydrogen bond network, though again triperiodic, is quite unlike that of $\left[\left(\mathrm{UO}_{2}\right)_{3}(123 \mathrm{btc})_{2}\left(\mathrm{H}_{2} \mathrm{O}\right)_{4}\right]$ and is associated with a simpler coordination polymer. As in compound $\mathbf{4}$, the $123 \mathrm{btc}^{3-}$ ligands in $\mathbf{5}$ are not involved in notable aromatic interactions, the packing (KPI, 0.71) being essentially dominated by hydrogen bonding.

An increase in periodicity may be achieved if the decorating groups as present in complex $\mathbf{5}$ are turned into bridging groups, which happens in the complex $\left[\left(\mathrm{UO}_{2}\right)_{3}(123 \mathrm{btc})_{2}(\mathrm{NMP})_{3}\right] \quad(6)$, where NMP is $\mathrm{N}$-methyl-2-pyrrolidone (Figure 6). The asymmetric unit contains six inequivalent uranium centres and four $123 \mathrm{btc}^{3-}$ ligands, although none of the inequivalent units are remarkably different. All uranium atoms are in pentagonal bipyramidal environments, with $\mathrm{U} 1, \mathrm{U} 2, \mathrm{U} 3$ and $\mathrm{U} 4$ being part of two binuclear units similar to those in $\mathbf{2 - 5}$ (i.e. with the aromatic rings on either side of the mean plane), while both U5 and U6 are bound to two carboxylate donors and three NMP molecules [U- 

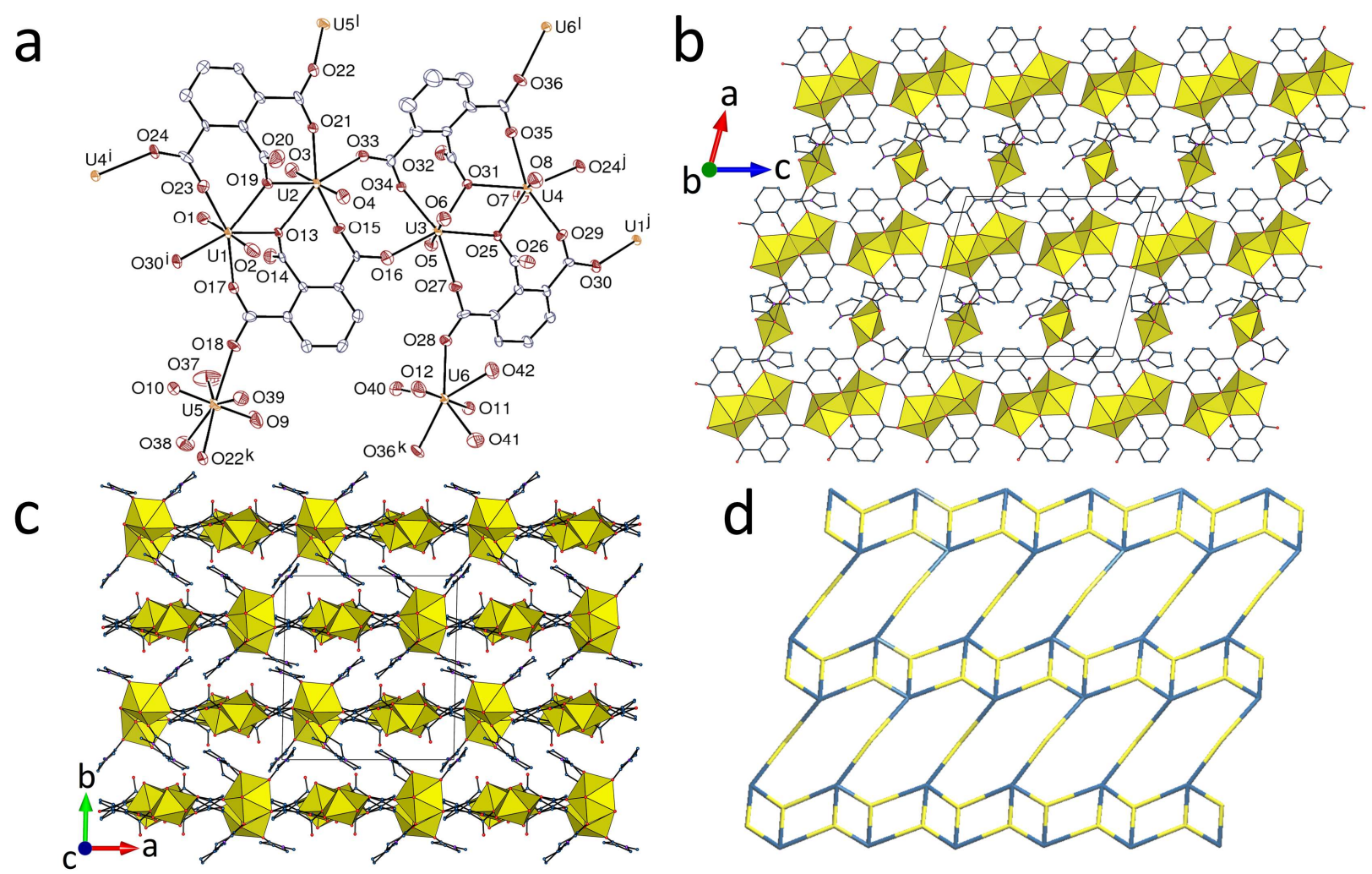

Figure 6. (a) View of complex 6 with displacement ellipsoids drawn at the $50 \%$ probability level. The nitrogen and carbon atoms of the NMP molecules and all hydrogen atoms are omitted. Symmetry codes: $\mathrm{i}=x, y, z-1 ; \mathrm{j}$ $=x, y, z+1 ; \mathrm{k}=x-1, y, z ; \mathrm{I}=x+1, y, z$. (b) View of the diperiodic network. (c) Packing with layers viewed edgeon and monoperiodic subunits viewed end-on. (d) Nodal representation of the network (yellow, uranium; blue, $\left.123 \mathrm{btc}^{3-}\right)$; same orientation as in part (b).

$\mathrm{O}$ (oxo), $\quad 1.748(10)-1.792(10) \quad \AA ; \quad \mathrm{U}-\mathrm{O}$ (carboxylato), $2.335(9)-2.440(8) \quad \AA ; \quad \mathrm{O}-\mathrm{O}(\mathrm{NMP})$, 2.317(12)-2.374(10) $\AA$ ]. The now usual strands run along [001] and they are cross-linked by the $\mathrm{UO}_{2}(\mathrm{NMP})_{3}{ }^{2+}$ groups to give a neutral, 2-nodal 3,4-c diperiodic network parallel to (010) which has the $\left\{4^{2} .6^{3} .8\right\}\left\{4^{2} .6\right\}$ point symbol and the $\mathrm{V}_{2} \mathrm{O}_{5}$ topological type. This is a common topology when uranyl-containing chains are bridged into a diperiodic network, and it is found also in complexes with benzene-1,2,4-tricarboxylate, although with a different ligand coordination mode and 3d-block metal ion bridges. ${ }^{[13]}$ Only one oxygen atom of the 2carboxylate group in each ligand is left uncoordinated, all the lateral ones being bound 
either to the uranium atoms in the strand or to the uranium bridges, so that coordinate bonds replace the hydrogen bond links between chains seen in $\mathbf{5}$. The equatorial planes of atoms $\mathrm{U} 5$ and $\mathrm{U} 6$ are strongly tilted with respect to the mean plane of the ribbons and as a result the NMP molecules protrude on both sides of the layers. The packing brings the "bumps" of one layer within the "hollows" of its neighbors (KPI, 0.66). No $\pi$-stacking interaction is present, and only some $\mathrm{CH} \cdots \pi$ interactions involving NMP molecules are possibly significant [C...centroid, 2.62 and $2.86 \AA$; $C-H \cdots$ centroid, 153 and $137^{\circ}$ ]. This structure is close to that of a diperiodic polymer formed by the uranyl ion with 5-nitrobenzene-1,2,3-tricarboxylate, ${ }^{[10]}$ with the three NMP molecules around the bridging cations replaced by water molecules, the nitro group being uncoordinated. Despite the absence of water, the structure of 6 can once more be regarded as exemplifying framework formation by hydrogen bond polymerization, as the diperiodic coordination polymer sheets are crosslinked by $\mathrm{CH} \cdots \mathrm{O}$ interactions involving the uncoordinated 2-carboxylate oxygen atoms as well as uranyl oxo groups and NMP methyl or methylene protons, all these interactions being apparent on the HS.

The structure of the complex $\left[\mathrm{NH}_{4}\right]\left[\mathrm{UO}_{2}(123 \mathrm{btc})\right](7)$ provides another instance, after complexes 1-3, of an anionic polymer and here there are some similarities to the structure of $\left[\left(\mathrm{UO}_{2}\right)_{3}(123 \mathrm{btc})_{2}\left(\mathrm{H}_{2} \mathrm{O}\right)_{4}\right]$ apparent in that the unique ligand unit forms only one 7membered chelate ring on uranium and the 2-carboxylate group, as usual nearperpendicular to the benzene ring, bridges two $U^{\mathrm{VI}}$ centres in an anti/anti $\mu_{2}-\kappa^{1} O: \kappa^{1} O^{\prime}$ mode (Figure 7). The unique uranium atom is in a pentagonal-bipyramidal environment, being also bound to three more carboxylate donors from the 1-, 2- and 3-carboxylate groups of three more ligands [U-O(oxo), 1.7788(12) and 1.7830(12) Å; U-O(carboxylato), 2.3593(11)- 


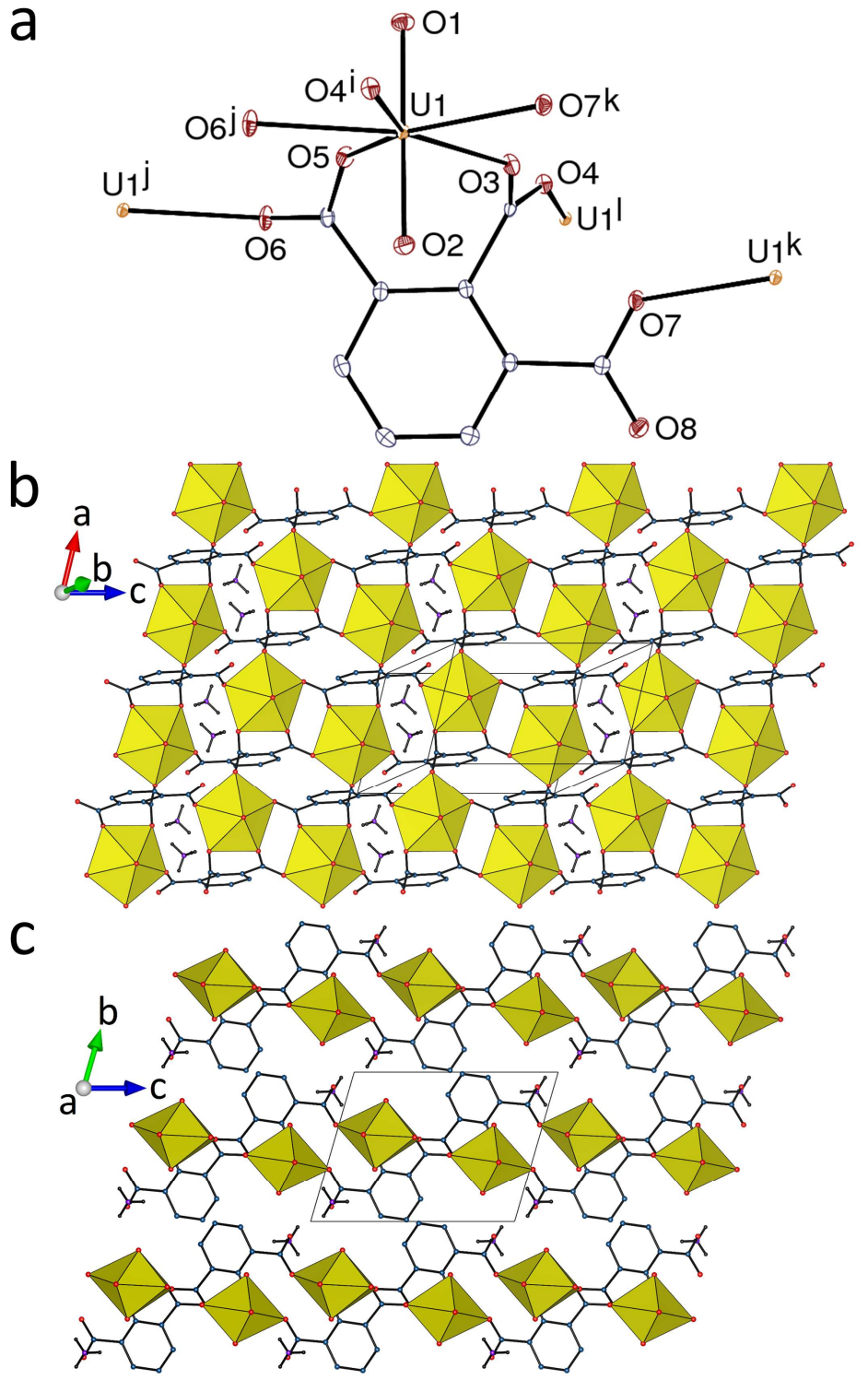

Figure 7. (a) View of complex 7 with displacement ellipsoids drawn at the $50 \%$ probability level. The counterion and hydrogen atoms are omitted. Symmetry codes: $\mathrm{i}=x+1, y, z ; \mathrm{j}=1-x, 1-y, 1-z ; \mathrm{k}=1-x, 1-y,-z ; \mathrm{I}=x-$ 1, $y, z$. (b) View of the diperiodic network. (c) Packing with layers viewed edge-on.

$2.4043(12) \AA]$. Only one carboxylate oxygen atom is thus left uncoordinated, but it is in a lateral group instead of in the central one as in $\mathbf{6}$. Both metal and ligand are thus 4-c nodes in the uninodal network formed, which is parallel to $(010)$ and has the $\left\{4^{4} .6^{2}\right\}$ point symbol and the common sql topological type. The aromatic rings are here nearly perpendicular to the sheets and they point on either side, but no intersheet $\pi$-stacking interaction is present. 
The ammonium cations are located above and below each sheet and they are involved in three conventional $\mathrm{NH} \cdots \mathrm{O}$ hydrogen bonds involving one uranyl oxo group and three carboxylato groups from three $123 \mathrm{btc}^{3-}$ ligands pertaining to two different sheets (one hydrogen atom giving a bifurcated bond and the uncoordinated atom 08 being an acceptor

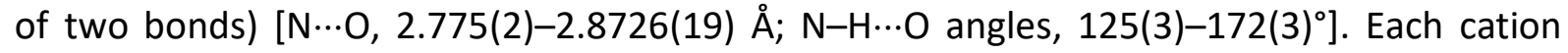
thus forms one $R_{1}{ }^{2}(6)$ ring with one sheet and one $R_{2}^{2}(10)$ ring with the other sheet, both rings containing one metal atom. Further, the ammonium groups are associated in centrosymmetric pairs forming $R_{4}^{2}(8)$ rings with two uncoordinated oxygen atoms pertaining to different layers (Figure 8). Besides these bonds, the HS indicates that the fourth ammonium proton is involved in an $\mathrm{NH} \cdots \pi$ interaction with an aromatic group. This complex is thus another example of a triperiodic hydrogen bonded polymer, the resulting packing being quite compact (KPI, 0.76).

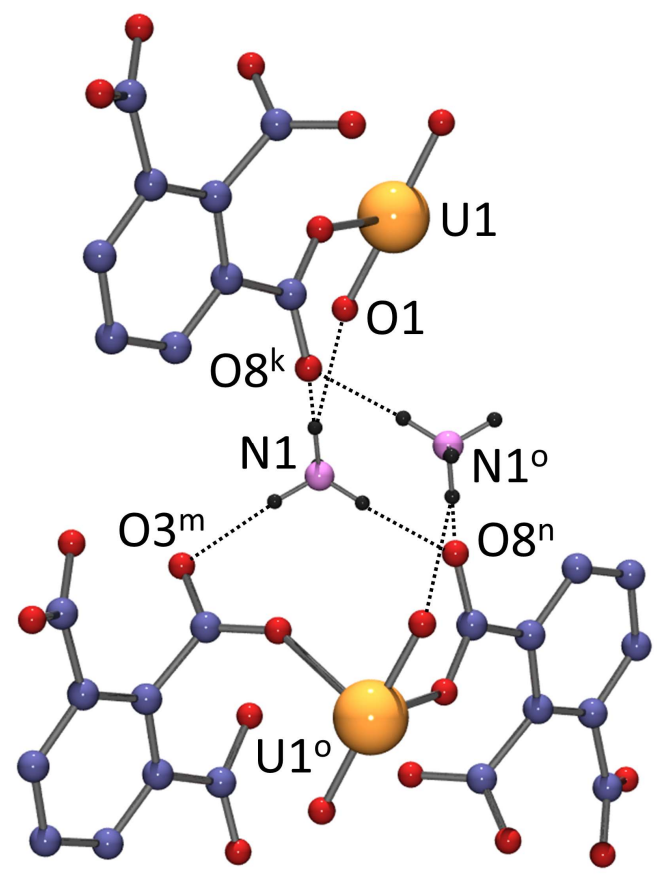

Figure 8. Bridging of layers by pairs of hydrogen-bonded ammonium cations in complex 7. Hydrogen bonds are shown as dotted lines. Symmetry codes: $\mathrm{k}=1-x, 1-y,-z ; \mathrm{m}=1-x, 2-y,-z ; \mathrm{n}=x+1, y+1, z ; 0=2-x, 2-y$, $-z$ 
The present results would seem to negate the idea that $123 \mathrm{btc}^{3-}$ is a ligand which particularly favours the formation of triperiodic polymers with uranyl ion. Certainly, it is a ligand where the 2-carboxylate group adopts an extreme deviation from coplanarity with the benzene ring and one which favours binding to $U^{\mathrm{Vl}}$ through formation of adjacent 7membered chelate rings to give binuclear complex units but in such uranyl complexes the uncoordinated 2-carboxylate oxygen atom appears in most cases to be involved in $\mathrm{O} \cdots \mathrm{HO}$, $\mathrm{O} \cdots \mathrm{HN}$ or $\mathrm{O} \cdots \mathrm{HC}$ interactions rather than further metal ion coordination. In the present series, the only significant disruption of the "double-phthalate" mode of bonding of $123 \mathrm{btc}^{3-}$ occurs in complex 7 , in the presence of the small and multiple $\mathrm{NH}$ donor, ammonium ion, to some extent resembling the coordinated water groups in $\left[\left(\mathrm{UO}_{2}\right)_{3}(123 \mathrm{btc})_{2}\left(\mathrm{H}_{2} \mathrm{O}\right)_{4}\right]$, where again the "double-phthalate" mode is not observed. That the stereochemistry of the hydrogen bond donor may determine its effect is indicated by the structure of complex $\mathbf{3}$, where the guanidinium cation, a good hydrogen bond donor but a planar entity, does not disrupt the "double-phthalate" mode nor even the polymerization of the $\left[\mathrm{UO}_{2}(123 \mathrm{btc})\right]_{2}{ }^{2-}$ entity.

It is notable that, while at least one carboxylate oxygen atom and as many as three are left uncoordinated in all the present uranyl ion complexes with $123 \mathrm{btc}^{3-}$, the only known case involving all donors being that of $\left[\left(\mathrm{UO}_{2}\right)_{3}(123 \mathrm{btc})_{2}\left(\mathrm{H}_{2} \mathrm{O}\right)_{4}\right]$, such a situation is less frequent with the $1,2,4$-isomer. ${ }^{[7,8,13,22]}$ Only three uranyl ion complexes with the $1,3,5$ isomer have been reported, ${ }^{[23]}$ and only one of them displays coordination of all oxygen atoms through tris $\left(\kappa^{2} O, O^{\prime}\right)$-chelation. ${ }^{[23 c]}$ Such reduction of the connectivity of polycarboxylates is not usual, and many examples are known in which the full coordination potential is reached. However, the case of $123 \mathrm{btc}^{3-}$ is reminiscent of that of the very 
different citrate ligand and its relatives malate and citramalate which most often act also as three-pronged donors (albeit with the central carboxylate replaced by an alkoxide) and have a marked tendency to give monoperiodic species based on a uranyl binuclear motif analogous to that found here, with however formation of two chelate rings of different sizes; ${ }^{[24]}$ in these cases also, the presence of uncoordinated carboxylate oxygen atoms is frequent, and they can also be used for further introduction of decorating or bridging cations. The propensity of all these three-pronged donors, whatever their differences, to give monoperiodic arrangements of binuclear uranyl ion complexes thus seems to be the determinant feature of their coordination behaviour towards this cation, with complex 7 only in the present series displaying a different connectivity. The most stable form of the binuclear species appears to be centrosymmetric or pseudo-centrosymmetric, and it is only in the discrete complex 1 that a cup-shaped arrangement is found. Overall, more variety and a more frequent occurrence of triperiodic frameworks is found with the 1,2,4-isomer, a ligand in which at least one of the two proximal carboxylate groups also deviates strongly from coplanarity with the aromatic ring, but which displays much less marked coordination preferences than $123 \mathrm{btc}^{3-}$.

\section{Conclusions}

We have reported here the syntheses and crystal structures of seven uranyl ion complexes with the benzene-1,2,3-tricarboxylate ligand, which display periodicities of zero, one or two, differing from the single triperiodic structure known previously. Overall, these structures reinforce the view of $123 \mathrm{btc}^{3-}$ as a "double-phthalate" ligand favouring, through further bridging donation, the formation of linear arrays based on binuclear $\left[\mathrm{UO}_{2}(123 \mathrm{btc})\right]_{2}{ }^{2-}$ subunits and, due to the large size of its chelate rings, pentagonal-bipyramidal coordination 
of $\mathrm{U}^{\mathrm{V}}$. The presence of uncoordinated carboxylate oxygen atoms in these linear arrays allows for the insertion of decorative or cross-linking metal-containing entities, with periodicity increase in the last case. One complex only does not display such dimercontaining chains and crystallizes as an anionic diperiodic network with ammonium counterions. Once again, study of a related series of uranyl complexes has shown that equatorial coordination to uranyl ion must be an interaction of comparable strength to "classical" hydrogen bonding and perhaps only competitive with the action of multiple weaker interactions, so that a variety of balance points can be reached depending upon the composition of the crystalline solid studied. This means in addition that it is somewhat artificial to consider such structures as based primarily upon the isolated coordination polymer that can be identified within them, although this is particularly convenient in regard to the ultimate identification of all operative factors.

\section{Experimental Section}

General: $\left[\mathrm{UO}_{2}\left(\mathrm{NO}_{3}\right)_{2}\left(\mathrm{H}_{2} \mathrm{O}\right)_{2}\right] \cdot 4 \mathrm{H}_{2} \mathrm{O}(\mathrm{RP}$ Normapur, 99\%) and 18-crown-6 were purchased from Prolabo. Benzene-1,2,3-tricarboxylic acid and $\mathrm{Zn}\left(\mathrm{NO}_{3}\right)_{2} \cdot 6 \mathrm{H}_{2} \mathrm{O}$ were from Aldrich, and 1,10phenanthroline was from Alfa-Aesar. The elemental analyses of complexes 2, 5 and $\mathbf{7}$ were performed by MEDAC Ltd. The low yields of the syntheses of the other complexes prevented further characterization. For all syntheses, the mixtures in demineralized water were placed in $10 \mathrm{~mL}$ tightly closed glass vessels and heated at $140{ }^{\circ} \mathrm{C}$ in a sand bath, under autogenous pressure. The crystals formed directly from the pressurized and heated reaction mixtures and not as a result of subsequent cooling. 
Caution! Uranium is a radioactive and chemically toxic element, and uranium-containing samples must be handled with suitable care and protection. Small quantities of reagents and solvents were employed to minimize any potential hazards arising both from the presence of uranium and the use of pressurized vessels for the syntheses.

$\left[\mathrm{Zn}(\text { phen })_{3}\right]\left[\mathrm{Zn}_{2}(123 \mathrm{btc})(\text { phen })_{4}\right]\left[\left(\mathrm{UO}_{2}\right)_{2}(123 \mathrm{btc})_{2}(\mathrm{OH})\left(\mathrm{CH}_{3} \mathrm{CN}\right)\right] \cdot 3 \mathrm{H}_{2} \mathrm{O}$ (1): $123 \mathrm{btcH}_{2}(21 \mathrm{mg}$, $0.10 \mathrm{mmol}),\left[\mathrm{UO}_{2}\left(\mathrm{NO}_{3}\right)_{2}\left(\mathrm{H}_{2} \mathrm{O}\right)_{2}\right] \cdot 4 \mathrm{H}_{2} \mathrm{O}(35 \mathrm{mg}, 0.07 \mathrm{mmol}), \mathrm{Zn}\left(\mathrm{NO}_{3}\right)_{2} \cdot 6 \mathrm{H}_{2} \mathrm{O}(30 \mathrm{mg}, 0.10$ $\mathrm{mmol})$, and 1,10-phenanthroline $(36 \mathrm{mg}, 0.20 \mathrm{mmol})$ were dissolved in a mixture of water $(1.0 \mathrm{~mL})$ and acetonitrile $(0.3 \mathrm{~mL})$, giving a few yellow crystals of complex 1 within one week.

[PPh $\left.{ }_{3} \mathrm{Me}\right]\left[\mathrm{UO}_{2}(\mathbf{1 2 3 b t c})\right]$ (2): $123 \mathrm{btcH}_{2}(21 \mathrm{mg}, 0.10 \mathrm{mmol}),\left[\mathrm{UO}_{2}\left(\mathrm{NO}_{3}\right)_{2}\left(\mathrm{H}_{2} \mathrm{O}\right)_{2}\right] \cdot 4 \mathrm{H}_{2} \mathrm{O}(35 \mathrm{mg}$, $0.07 \mathrm{mmol})$, and $\mathrm{PPh}_{3} \mathrm{MeBr}(36 \mathrm{mg}, 0.10 \mathrm{mmol})$ were dissolved in a mixture of water $(0.7 \mathrm{~mL})$ and DMF (0.2 mL), giving yellow crystals of complex 2 overnight (34 mg, 64\% yield based on U). $\mathrm{C}_{28} \mathrm{H}_{21} \mathrm{O}_{8} \mathrm{PU}$ (754.45): calcd. C 44.58, H 2.81; found C 44.17, H 2.67.

$\left[\mathrm{C}\left(\mathrm{NH}_{2}\right)_{3}\right]\left[\mathrm{UO}_{2}(\mathbf{1 2 3 b t c})\right] \cdot 0.5 \mathrm{H}_{2} \mathrm{O}(3): 123 \mathrm{btcH}_{2}(21 \mathrm{mg}, 0.10 \mathrm{mmol}),\left[\mathrm{UO}_{2}\left(\mathrm{NO}_{3}\right)_{2}\left(\mathrm{H}_{2} \mathrm{O}\right)_{2}\right] \cdot 4 \mathrm{H}_{2} \mathrm{O}$ (35 mg, $0.07 \mathrm{mmol}$ ), and $\mathrm{C}\left(\mathrm{NH}_{2}\right)_{3} \mathrm{NO}_{3}(24 \mathrm{mg}, 0.20 \mathrm{mmol}$ ) were dissolved in a mixture of water $(0.7 \mathrm{~mL})$ and DMF $(0.2 \mathrm{~mL})$, giving a few yellow crystals of complex 3 after three months.

$\left[\mathrm{UO}_{2}(\mathbf{1 2 3 b t c}) \mathrm{K}(\mathbf{1 8 C 6})\right] \cdot \mathrm{H}_{2} \mathrm{O}$ (4): $123 \mathrm{btcH}_{2}(21 \mathrm{mg}, 0.10 \mathrm{mmol}),\left[\mathrm{UO}_{2}\left(\mathrm{NO}_{3}\right)_{2}\left(\mathrm{H}_{2} \mathrm{O}\right)_{2}\right] \cdot 4 \mathrm{H}_{2} \mathrm{O}(35$ $\mathrm{mg}, 0.07 \mathrm{mmol}), \mathrm{KNO}_{3}(20 \mathrm{mg}, 0.20 \mathrm{mmol})$, and 18-crown-6 (53 mg, $0.20 \mathrm{mmol}$ ) were dissolved in a mixture of water $(0.7 \mathrm{~mL})$ and $\mathrm{DMF}(0.2 \mathrm{~mL})$, giving a few yellow crystals of complex 4 after three months. 
$\left[\left(\mathrm{UO}_{2}\right)_{3}(\mathbf{1 2 3 b t c})_{2}(\mathrm{DMF})_{2}\left(\mathrm{H}_{2} \mathrm{O}\right)_{2}\right] \quad$ (5): $\quad 123 \mathrm{btcH}_{2} \quad(21 \quad \mathrm{mg}, \quad 0.10 \quad \mathrm{mmol}), \quad$ and $\left[\mathrm{UO}_{2}\left(\mathrm{NO}_{3}\right)_{2}\left(\mathrm{H}_{2} \mathrm{O}\right)_{2}\right] \cdot 4 \mathrm{H}_{2} \mathrm{O}(50 \mathrm{mg}, 0.10 \mathrm{mmol})$ were dissolved in a mixture of water $(0.7 \mathrm{~mL})$ and DMF $(0.2 \mathrm{~mL})$, giving yellow crystals of complex 5 overnight ( $4 \mathrm{mg}, 9 \%$ yield based on $\mathrm{U})$. $\mathrm{C}_{24} \mathrm{H}_{24} \mathrm{~N}_{2} \mathrm{O}_{22} \mathrm{U}_{3}$ (1406.54): calcd. C 20.49, $\mathrm{H} 1.72$, N 1.99; found $\mathrm{C} 20.40, \mathrm{H} 1.76, \mathrm{~N} 2.01$. The yield was not improved upon more prolonged heating.

$\left[\left(\mathrm{UO}_{2}\right)_{3}(123 \mathrm{btc})_{2}(\mathrm{NMP})_{3}\right](6): 123 \mathrm{btcH} \mathrm{H}_{2}(21 \mathrm{mg}, 0.10 \mathrm{mmol})$, and $\left[\mathrm{UO}_{2}\left(\mathrm{NO}_{3}\right)_{2}\left(\mathrm{H}_{2} \mathrm{O}\right)_{2}\right] \cdot 4 \mathrm{H}_{2} \mathrm{O}(50$ $\mathrm{mg}, 0.10 \mathrm{mmol})$ were dissolved in a mixture of water $(0.7 \mathrm{~mL})$ and NMP $(0.2 \mathrm{~mL})$, giving a few yellow crystals of complex 6 within one week.

$\left[\mathrm{NH}_{4}\right]\left[\mathrm{UO}_{2}\right.$ (123btc)] (7): $123 \mathrm{btcH}_{2}(21 \mathrm{mg}, 0.10 \mathrm{mmol}),\left[\mathrm{UO}_{2}\left(\mathrm{NO}_{3}\right)_{2}\left(\mathrm{H}_{2} \mathrm{O}\right)_{2}\right] \cdot 4 \mathrm{H}_{2} \mathrm{O}(35 \mathrm{mg}, 0.07$ mmol), and $\mathrm{NH}_{4} \mathrm{NCS}(15 \mathrm{mg}, 0.20 \mathrm{mmol})$ were dissolved in a mixture of water $(0.7 \mathrm{~mL})$ and acetonitrile $(0.2 \mathrm{~mL}$ ), giving yellow crystals of complex 7 within one week ( $26 \mathrm{mg}, 75 \%$ yield based on U). $\mathrm{C}_{9} \mathrm{H}_{7} \mathrm{NO}_{8} \mathrm{U}$ (495.19): calcd. C 21.83, $\mathrm{H}$ 1.42, $\mathrm{N} 2.83$; found $\mathrm{C} 21.62, \mathrm{H} \mathrm{1.51,} \mathrm{N}$ 2.72 .

Crystallography: The data were collected at 100(2) K on a Bruker D8 Quest diffractometer equipped with an Incoatec Microfocus Source (I $\mathrm{\mu S}$ S.0 Mo) and a PHOTON III area detector, and operated through the APEX3 software. ${ }^{[25]}$ The data were processed with SAINT ${ }^{[26]}$ and absorption effects were corrected for empirically with SADABS. ${ }^{[27]}$ The structures were solved by intrinsic phasing with SHELXT ${ }^{[28]}$ and refined by full-matrix least-squares on $F^{2}$ with SHELXL, ${ }^{[29]}$ using the ShelXle interface. ${ }^{[30]}$ All non-hydrogen atoms were refined with anisotropic displacement parameters. In complexes $\mathbf{3}, \mathbf{4}$, and $\mathbf{5}$, the hydrogen atoms bound 
to oxygen or nitrogen atoms were found on a residual electron density map and they were refined with restraints on bond lengths and with isotropic displacement parameters equal to $1.2\left(\mathrm{NH}_{2}\right)$ or $1.5\left(\mathrm{H}_{2} \mathrm{O}\right)$ times that of the parent atom. The hydrogen atoms bound to the nitrogen atom in $\mathbf{7}$ were found and fully refined with no restraint. The carbon-bound hydrogen atoms were introduced at calculated positions and were treated as riding atoms with an isotropic displacement parameter equal to 1.2 times that of the parent atom (1.5 for $\mathrm{CH}_{3}$, with optimized geometry). Crystal data and structure refinement parameters are given in Table 1. The molecular plots were drawn with ORTEP-3 ${ }^{[31]}$ and the polyhedral representations with VESTA. ${ }^{[32]}$ Topological analyses were made with ToposPro. ${ }^{[33]}$ Special details for two of the complexes are as follows.

Complex 1. The hydroxide anion (09) and an acetonitrile molecule are disordered over the same uranium coordination site; they were given occupancy parameters of 0.5 for charge balance and they were refined with restraints on bond lengths and displacement parameters. One water solvent molecule (014) was also given an occupancy parameter of 0.5 since it is too close to the disordered acetonitrile molecule. Another water molecule (015) was given 0.5 occupancy so as to retain an acceptable displacement parameter, and another one (016) is disordered over two positions. The hydroxide and water hydrogen atoms were not found.

Complex 6. The crystals were extremely thin and of poor quality. Whatever the absorption correction applied (multi-scan or numerical), large electron density peaks remain, in particular (but not only) close to the uranium atoms. Restraints on displacement parameters and some bond lengths had to be applied, particularly for three NMP molecules. 
Deposition Numbers 2116868 (for 1), 2116869 (for 2), and 2116870 (for 3), 2116871 (for 4), 2116872 (for 5), 2116873 (for 6), and 2116874 (for 7) contain the supplementary crystallographic data for this paper. These data are provided free of charge by the joint Cambridge Crystallographic Data Centre and Fachinformationszentrum Karlsruhe Access Structures service www.ccdc.cam.ac.uk/structures.

Table 1. Crystal data and structure refinement details.

\begin{tabular}{|c|c|c|c|c|c|c|c|}
\hline & 1 & 2 & 3 & 4 & 5 & 6 & 7 \\
\hline Empirical formula & $\mathrm{C}_{113} \mathrm{H}_{73} \mathrm{~N}_{15} \mathrm{O}_{29} \mathrm{U}_{2} \mathrm{Zn}_{3}$ & $\mathrm{C}_{28} \mathrm{H}_{21} \mathrm{O}_{8} \mathrm{PU}$ & $\mathrm{C}_{10} \mathrm{H}_{10} \mathrm{~N}_{3} \mathrm{O}_{8.5} \mathrm{U}$ & $\mathrm{C}_{21} \mathrm{H}_{29} \mathrm{KO}_{15} \mathrm{U}$ & $\mathrm{C}_{24} \mathrm{H}_{24} \mathrm{~N}_{2} \mathrm{O}_{22} \mathrm{U}_{3}$ & $\mathrm{C}_{33} \mathrm{H}_{33} \mathrm{~N}_{3} \mathrm{O}_{21} \mathrm{U}_{3}$ & $\mathrm{C}_{9} \mathrm{H}_{7} \mathrm{NO}_{8} \mathrm{U}$ \\
\hline$M\left(\mathrm{~g} \mathrm{~mol}^{-1}\right)$ & 2777.03 & 754.45 & 546.24 & 798.57 & 1406.54 & 1521.71 & 495.19 \\
\hline Crystal system & monoclinic & monoclinic & triclinic & monoclinic & triclinic & triclinic & triclinic \\
\hline Space group & $C 2 / c$ & $P 2_{1} / n$ & $P_{\bar{I}}^{\bar{I}}$ & $P 2_{1} / n$ & $P 1$ & $P_{\overline{\mathrm{I}}}$ & $P_{\overline{\mathrm{I}}}$ \\
\hline$a(\AA)$ & $14.4274(4)$ & $8.9543(5)$ & $8.8962(8)$ & $13.6873(5)$ & $8.8879(4)$ & $15.3610(12)$ & $6.7484(3)$ \\
\hline$b(\AA)$ & $33.6581(11)$ & $12.4282(7)$ & $11.7505(10)$ & $8.8742(3)$ & $9.0733(4)$ & $15.9804(13)$ & $8.3615(3)$ \\
\hline$c(\AA \AA)$ & $21.6074(7)$ & $23.3176(13)$ & $13.9306(11)$ & $21.7996(9)$ & $11.4479(5)$ & $17.7062(13)$ & $10.8176(4)$ \\
\hline$\alpha\left({ }^{\circ}\right)$ & 90 & 90 & $82.378(4)$ & 90 & $73.5286(17)$ & $84.084(4)$ & $70.9643(12)$ \\
\hline$\beta\left(\left(^{\circ}\right)\right.$ & $99.4362(15)$ & $101.044(2)$ & $77.893(4)$ & $99.279(2)$ & $71.9306(16)$ & $74.669(3)$ & $76.3860(12)$ \\
\hline$\gamma\left({ }^{\circ}\right)$ & 90 & 90 & $85.490(4)$ & 90 & $72.3471(16)$ & $87.370(4)$ & $73.9166(12)$ \\
\hline$V\left(\AA^{3}\right)$ & $10350.6(6)$ & $2546.9(2)$ & $1409.3(2)$ & $2613.22(17)$ & $817.83(6)$ & $4168.6(6)$ & $547.33(4)$ \\
\hline$z$ & 4 & 4 & 4 & 4 & 1 & 4 & 2 \\
\hline Reflections collected & 182032 & 88221 & 98548 & 124652 & 115401 & 292344 & 61438 \\
\hline Independent reflections & 9830 & 4830 & 5348 & 7969 & 8363 & 15829 & 3292 \\
\hline Observed reflections $[I>2 \sigma(I)]$ & 9351 & 4693 & 4689 & 7239 & 8320 & 13244 & 3288 \\
\hline$R_{\text {int }}$ & 0.037 & 0.046 & 0.070 & 0.069 & 0.036 & 0.118 & 0.048 \\
\hline Parameters refined & 762 & 345 & 448 & 349 & 477 & 1087 & 188 \\
\hline$R_{1}$ & 0.044 & 0.025 & 0.024 & 0.020 & 0.018 & 0.057 & 0.011 \\
\hline$w R_{2}$ & 0.102 & 0.063 & 0.055 & 0.045 & 0.039 & 0.137 & 0.025 \\
\hline$s$ & 1.179 & 1.287 & 1.103 & 1.045 & 1.051 & 1.097 & 1.164 \\
\hline$\Delta \rho_{\min }\left(\mathrm{e} \AA^{-3}\right)$ & -1.56 & -0.95 & -1.11 & -0.71 & -0.83 & -2.85 & -0.74 \\
\hline$\Delta \rho_{\max }\left(\mathrm{e} \AA^{-3}\right)$ & 2.26 & 1.98 & 1.76 & 0.86 & 2.32 & 5.80 & 0.84 \\
\hline
\end{tabular}

\section{Conflict of Interest}

The authors declare no conflict of interest.

Keywords: Carboxylic acids / Metal-organic networks / Structure elucidation / Tricarboxylate ligands / Uranyl cation

\section{References}

[1] K. X. Wang, J. S. Chen, Acc. Chem. Res. 2011, 44, 531-540. 
[2] M. B. Andrews, C. L. Cahill, Chem. Rev. 2013, 113, 1121-1136.

[3] T. Loiseau, I. Mihalcea, N. Henry, C. Volkringer, Coord. Chem. Rev. 2014, 266-267, 69109.

[4] J. Su, J. S. Chen, Struct. Bond. 2015, 163, 265-296.

[5] P. Thuéry, J. Harrowfield, Dalton Trans. 2017, 46, 13660-13667.

[6] K. Lv, S. Fichter, M. Gu, J. März, M. Schmidt, Coord. Chem. Rev. 2021, 446, 214011.

[7] Z. L. Liao, G. D. Li, X. Wei, Y. Yu, J. S. Chen, Eur. J. Inorg. Chem. 2010, 3780-3788.

[8] A. B. Yusov, M. N. Sokolova, M. S. Grigor'ev, A. M. Fedoseev, N. A. Budantseva, P. Moisy, Radiochemistry 2012, 54, 105-114.

[9] M. Dufaye, N. P. Martin, S. Duval, C. Volkringer, A. Ikeda-Ohno, T. Loiseau, RSC Advances 2019, 9, 22795-22804.

[10] X. Tong, S. Wang, J. Zuo, Y. Ge, Q. Gao, S. Liu, J. Ding, F. Liu, J. Luo, J. Xiong, Chin. Chem. Lett. 2021, 32, 604-608.

[11] a) Z. T. Yu, Z. L. Liao, Y. S. Jiang, G. H. Li, J. S. Chen, Chem. Eur. J. 2005, 11, 2642-2650; b) G. E. Gomez, D. Onna, R. F. D'vries, B. C. Barja, J. Ellena, G. E. Narda, G. J. A. A. Soler-Illia, J. Mater. Chem. C 2020, 8, 11102-11109; c) X. Zhang, P. Li, M. Krzyaniak, J. Knapp, M. R. Wasielewski, O. K. Farha, Inorg. Chem. 2020, 59, 16795-16798.

[12] P. Thuéry, J. Harrowfield, Cryst. Growth. Des. 2021, 21, 3000-3013, and references therein.

[13] P. Thuéry, Y. Atoini, J. Harrowfield, Cryst. Growth Des. 2020, 20, 7368-7383.

[14] a) R. Taylor, O. Kennard, J. Am. Chem. Soc. 1982, 104, 5063-5070; b) G. R. Desiraju, Acc. Chem. Res. 1996, 29, 441-449.

[15] A. L. Spek, Acta Crystallogr., Sect. D 2009, 65, 148-155.

[16] M. A. Spackman, D. Jayatilaka, CrystEngComm 2009, 11, 19-32. 
[17] S. K. Wolff, D. J. Grimwood, J. J. McKinnon, M. J. Turner, D. Jayatilaka, M. A. Spackman, CrystalExplorer; University of Western Australia: Crawley, Australia, 2012.

[18] I. Dance, M. Scudder, Chem. Eur. J. 1996, 2, 481-486.

[19] a) M. C. Etter, J. C. MacDonald, J. Bernstein, Acta Crystallogr., Sect. B 1990, 46, 256262; b) J. Bernstein, R. E. Davis, L. Shimoni, N. L. Chang, Angew. Chem. Int. Ed. 1995, 34, 1555-1573.

[20] a) C. R. Groom, I. J. Bruno, M. P. Lightfoot, S. C. Ward, Acta Crystallogr., Sect. B 2016, 72, 171-179; b) R. Taylor, P. A. Wood, Chem. Rev. 2019, 119, 9427-9477.

[21] P. Li, M. R. Ryder, J. F. Stoddart, Acc. Mater. Res. 2020, 1, 77-87.

[22] Y. Zhang, L. Chen, J. Guan, X. Wang, S. Wang, J. Diwu, Dalton Trans. 2020, 49, 36763679.

[23] a) L. A. Borkowski, C. L. Cahill, Acta Crystallogr., Sect. E 2004, 60, m198-m200; b) Y. Wang, X. Yin, W. Liu, J. Xie, J. Chen, M. A. Silver, D. Sheng, L. Chen, J. Diwu, N. Liu, Z. Chai, T. E. Albrecht-Schmitt, S. Wang, Angew. Chem. Int. Ed. 2018, 57, 7883-7887; c) Y. Dai, H. M. Chai, R. X. Zhang, J. A. Min, Z. Wang, M. Zhang, Y. Zhang, J. Feng, C. Zhang, J. Wang, Inorg. Chem. Commun. 2020, 111, 107628.

[24] a) P. Thuéry, Inorg. Chem. 2007, 46, 2307-2315; b) E. Cole, E. Flores, M. Basile, A. Jayasinghe, J. de Groot, D. K. Unruh, T. Z. Forbes, Polyhedron 2016, 114, 378-384; c) P. Thuéry, J. Harrowfield, Eur. J. Inorg. Chem. 2018, 1016-1027.

[25] Bruker AXS, APEX3, Version 2019.1-0, Madison, Wisconsin, USA, 2019.

[26] Bruker Nano, Inc. SAINT, Version 8.40A, Madison, Wisconsin, USA, 2019.

[27] a) Bruker AXS, SADABS, Version 2016/2, Madison, Wisconsin, USA, 2016; b) L. Krause, R. Herbst-Irmer, G. M. Sheldrick, D. Stalke, J. Appl. Crystallogr. 2015, 48, 3-10.

[28] G. M. Sheldrick, Acta Crystallogr., Sect. A 2015, 71, 3-8. 
[29] G. M. Sheldrick, Acta Crystallogr., Sect. C 2015, 71, 3-8.

[30] C. B. Hübschle, G. M. Sheldrick, B. Dittrich, J. Appl. Crystallogr. 2011, 44, 1281-1284.

[31] a) M. N. Burnett, C. K. Johnson, ORTEPIII, Report ORNL-6895, Oak Ridge National Laboratory, Tennessee, USA, 1996; b) L. J. Farrugia, J. Appl. Crystallogr. 2012, 45, 849-854.

[32] K. Momma, F. Izumi, J. Appl. Crystallogr. 2011, 44, 1272-1276.

[33] V. A. Blatov, A. P. Shevchenko, D. M. Proserpio, Cryst. Growth Des. 2014, 14, 35763586. 


\title{
Uranyl Ion Coordination by Benzene-1,2,3-tricarboxylate: Building Chains and Networks from Binuclear Bricks
}

\author{
Pierre Thuéry, Jack Harrowfield
}

Key Topic: Uranyl complexes

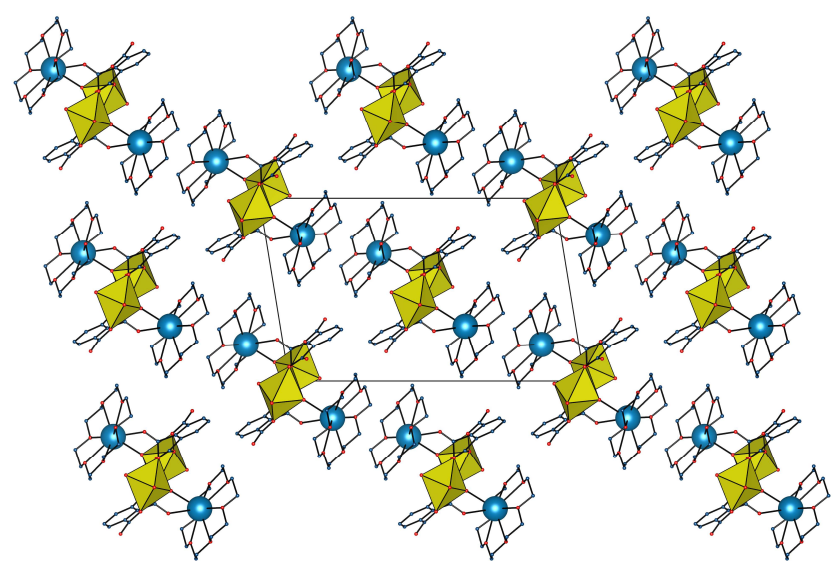

Zero-, mono- and diperiodic uranyl ion complexes are formed by benzene-1,2,3tricarboxylate, depending on the structure-directing species used, linear chains based on dimeric motifs being a preferred arrangement. 